УДК 556.314

DOI: $10.17223 / 25421379 / 1 / 6$

\title{
С.Л. Шварцев
}

Томский филиал Института нефтегазовой геологии и геофизики им. А.А. Трофимука СО РАН, Томск, Россия

Начиональныий исследовательский

Томский политехнический университет, Томск, Россия

\section{ВЕДУЩИЕ МЕХАНИЗМЫ ФОРМИРОВАНИЯ ВТОРИЧНЫХ ПРОДУКТОВ В ЗОНЕ ГИПЕРГЕНЕЗА: ОБЩНОСТЬ И ВЗАИМОСВЯЗЬ ИХ ГЕНЕЗИСА}

\begin{abstract}
Показано, что в верхней части земной коры основные процессы глобальной эволюиии начались взаимодействием воды и базальтов, возникла равновеснонеравновесная система внутренне противоречивая способная геологически вечно развиваться по строгим законам термодинамики независимо ни от каких внешних факторов. При этом вода выступает ведущим фактором преобразования этой системы. После появления фотосинтеза органические соединения оказывались в разных геохимических средах, созданных взаимодействием воды с базальтами, что определило их дальнейшее преобразование по схеме, близкой $\kappa$ той, которая обеспечила эволючию горных пород. При этом единым связующим звеном между косной и биокосной материей выступает вода, контролирующая главную стадию эволюиии в геологической и биологической системах - образование принциипильно новых соединений.

Ключевые слова: зона гипергенеза, глобальная эволючия, термодинамическое равновесие, гидрогеохимия, вторичное минералообразование, система вода-порода, растворение, подземные воды.
\end{abstract}

Зона гипергенеза - это наиболее изученная и освоенная человеком верхняя часть нашей планеты. Практически все науки о земле, а также подавляющее большинство естественных изучают эту зону в течение нескольких столетий. При этом число наук, изучающих зону происхождения жизни и наиболее активной деятельности человека, непрерывно возрастало и продолжает расти. Каждая из возникающих наук выработала свои методы, подходы и пути решения проблем, связанных с функционированием какоголибо одного объекта (почвы, леса, реки, озера, болота, коры выветривания, ландшафта, живого организма и т.д.), накопила массу фактов, которые пытается как-то систематизировать и классифицировать, найти ведущие факторы и процессы, определяющие генезис, становление, развитие объекта исследований. В результате каждая наука оперирует своими терминами, понятиями, определениями, за которыми кроются многочисленные процессы, факторы, механизмы, явления, обстановки, среды, соединения, минералы, 
растворы, типы, виды, разновидности живых и неживых объектов, субъектов, ландшафтов, различных сфер.

Все компоненты этой зоны непрерывно взаимодействуют между собой. В результате этого одни соединения разрушаются, другие формируются, одни уносятся за пределы этой зоны, другие, наоборот, приносятся из соседних зон, третьи видоизменяются, превращаясь в принципиально новые. Но при этом важно, что идет непрерывный процесс преобразования любого вещества, начиная от горной породы и воды и кончая живой клеткой и человеком. И не просто преобразование, а непрерывное усложнение всего окружающего мира, каждого его компонента, соединения, объекта, субъекта. Это до конца не осознанное наукой преобразование окружающего мира известный английский биолог Р. Докинз назвал самым грандиозным шоу на земле [3]. Тем самым поставлена точка в признании наличия грандиозной эволюции на нашей планете. Теперь уже никто не сомневается, что наш окружающий мир постоянно эволюционирует не от сложного к простому, как раньше думали многие, а от простого ко все более сложному.

\section{Краткий исторический аспект проблемы}

Признав, после долгих сомнений, эволюцию окружающего мира, наука резко обострила проблему движущих сил такой эволюции, природы и механизмов их действия. Не понимая механизмы эволюции, мы не знаем, когда они возникли, что послужило толчком для этого события и какие силы движут эволюцией сегодня. Вот что пишет по этому поводу тот же Р. Докинз: «Свидетельств относительно момента начала эволюции на планете у нас нет. Это могло быть событие невероятной редкости: ведь произойти оно должно было всего однажды, и, насколько мы знаем, так это и есть. Более того, возможно, оно произошло единственный раз во вселенной» [Там же. C. 429].

Конечно, наука давно ищет силы, которые движут эволюцией. Так, еще Ж.-Б. Ламарк в конце XVIII в., изучая направленность преобразования окружающего мира, с удивлением констатировал, что в природе, на первый взгляд, доминируют разрушительные процессы: сложные вещества трансформируются в простые, которые в дальнейшем не разрушаются, а накапливаются в разных соединениях. Но откуда в таком случае берутся сложные? Анализируя эту проблему, Ж.-Б. Ламарк пришел к выводу, что в природе, кроме тенденции к дезинтеграции, разрушению, существует противоположный процесс, направленный на формирование сложных веществ. Но какая сила движет этим процессом усложнения и какова ее природа, он не мог найти в окружающем мире и дать ответ на этот вопрос. Тогда он предположил, что такая неизвестная сила скрыта в живых телах и она характерна только для растений, животных и человека. Поэтому он назвал её властью жизни (pouvoir de la vie) и рассматривал в качестве демаркационного фактора, разделяющего природу на живую и неживую. Появление сложных ве- 
ществ в мертвой материи Ж.Б. Ламарк объяснял тем, что они являются продуктами жизни. Так более двух столетий назад был поставлен вопрос о механизмах формирования сложностей, остающийся по сей день одним из ключевых в науке [6].

Идеи Ж.-Б. Ламарка оказались настолько убедительными, что даже такой проницательный ученый, как В.И. Вернадский, не признавал наличия эволюции в неживой материи и объяснял наблюдаемые изменения в верхней части земной коры взаимодействием в системе вода-порода-газ-органическое вещество. При этом он считал, что вода, которая обладает многими совершенно необычными свойствами, выступает главным компонентом таких преобразований в биокосной материи [2].

Ч. Дарвин в своей знаменитой книге «Происхождение видов путем естественного отбора» отверг идею жизненной силы и взамен предложил механизм эволюции путем естественного отбора, физический или химический смысл которого до сих пор не раскрыт. Тем не менее тот же Р. Докинз ярый поклонник и пропагандист учения Ч. Дарвина, убежден, что эволюция путем естественного отбора - по сей день единственный известный нам способ, которым из простого начала получается сложное [3]. Под естественным отбором, как известно, Ч. Дарвин понимал неслучайное сохранение случайных изменений. Возможно ли такое? Ведь речь идет о создании и непрерывном усложнении окружающего мира, формировании неизвестных ранее соединений (минеральных и органических), возникновении жизни, о новых процессах и механизмах взаимодействия, усложнении связей между компонентами ландшафта да и всего окружающего мира. В результате эволюции созданы миллиарды органических соединений, клеток, бактерий, растений, животных, людей, разум человека, сама жизнь. И это шоу возникло случайно? Разве можно в это поверить в эпоху ноосферы, в век небывалого развития науки и здравого смысла?! Думаю, что нет. Тем более что ответов на вопросы когда, где и в результате какого события возникло это грандиозное шоу - до сих пор нет.

Хотя теория естественного отбора сегодня не удовлетворяет многих ученых, но классическая биология до сих пор придерживается этого постулата. Эта идея оказалась живучей, потому что другого, более обоснованного механизма до сих пор никто не предложил: наука ищет в основном пути ее дополнительного обоснования. Так, например, Е.В. Кунин, который в своей нашумевшей книге [4] хотя и провел переоценку отдельных положений эволюционной концепции Ч. Дарвина, но базовая сущность естественного отбора сохранилась. Более того, он обосновывает гипотезу, в соответствии с которой случайности имеют свои закономерности, которые на разных этапах эволюции определяются разными факторами. При этом «случайное появление даже очень сложных систем не только возможно, но и неизбежно» [4. С. 1038]. Такие примеры можно продолжать.

Неудивительно поэтому, что в мире гуляют такие фантастические гипотезы, как, например, концепция Гайя, разработанная британским ученым Дж. Ловлоком еще в 1972 г. [16]. Суть этой гипотезы в том, что биосфера 
Земли представляет собой якобы самоорганизующуюся систему, которая через деятельность бактерий регулирует содержание $\mathrm{CO}_{2}$ в атмосфере и тем самым воздействует на климат нашей планеты. Еще более удивительно, что в эту гипотезу поверил академик В.Е. Хаин, который, опираясь на идею, что живые организмы преобразуют лучистую энергию Солнца в химическую, предположил, что химическая энергия, в свою очередь, через процессы выветривания и субдукционное погружение горных пород расходуется на трансформацию базальтов в граниты или, другими словами, на формирование земной коры. Отсюда он делает вывод, что «нашу Землю, включая ее атмосферу в единстве с биосферой, следует рассматривать как единую самоорганизующуюся систему» [9. С. 796].

С таким подходом академика вряд ли можно согласиться: чтобы земные оболочки могли взаимодействовать, они сначала должны возникнуть. Развитие Земли не могло начаться с взаимодействия с биосферой, которой на планете не было. Да и в целом признание ведущей роли биосферы в развитии Земли означает тупиковую ситуацию в объяснении происхождения самой биосферы: спрашивается, откуда взялась биосфера, если эволюция на нашей планете началась с ее появлением? Замкнутый круг, который ведет к креационизму.

С появлением синергетики наука стала искать не отличие живого от неживого, а их общность. В этом плане достигнуты определенные успехи, хотя проблема того, как у целого возникают эти свойства, которых нет у его частей, пока далека от решения $[6,7]$.

В соответствии с положениями синергетики в мире существует большой класс диссипативных структур. Развиваясь в сильно неравновесных условиях и активно взаимодействуя с внешней средой с поглощением энергии, эти структуры при определенных обстоятельствах могут переходить в более сложные, динамические состояния, совершать скачок от хаоса к порядку. Для диссипативных структур характерны нелинейное развитие, необратимость эволюции, рост устойчивости, способность к последовательной смене упорядоченных состояний и их непрерывному усложнению при условии получения из внешней среды большей энергии по сравнению с той, что требовалась для поддержания предыдущего состояния.

Новый подход к пониманию эволюционных процессов позволяет смягчить традиционно жёсткое противопоставление живой и неживой материи и открывает путь к более плодотворному поиску механизмов возникновения жизни и её дальнейшей эволюции. Все это, конечно, свидетельствует о значительном прогрессе в понимании механизмов глобальной эволюции, но, по нашему мнению, не устраняет основные причины сложившегося положения в науке. Последние обусловлены: 1) непризнанием до сих пор наличия эволюции в неживой материи и 2) полным игнорированием роли воды как ведущего фактора эволюции. 


\section{Природа эволюции в системе вода-базальты}

В последние 20-30 лет в изучении роли воды в эволюции окружающего мира достигнуты значительные успехи [8, 13]. В частности, нами установлено, что система вода-порода всегда является равновесно-неравновесной: вода часто неравновесна преимущественно с минералами магматических пород, которые она растворяет, но одновременно всегда равновесна с вторичными минералами, которые она формирует. Иначе говоря, система водапорода является внутренне противоречивой, способной к самопроизвольному, непрерывному, геологически длительному развитию с образованием принципиально новых минеральных фаз и геохимических типов воды. Эта система развивается постоянно в нелинейной области термодинамической ветви в условиях, далеких от равновесия, и относится к типу абиогенных диссипативных структур, играющих совершенно особую роль в прогрессивном развитии косной материи [10].

Еще более важно, что с некоторыми ведущими минералами эндогенного генезиса равновесие воды в принципе невозможно. Удивительно и то, что в эту группу входят минералы, слагающие базальты, т.е. силикаты и алюмосиликаты $\mathrm{Ca}, \mathrm{Mg}$ и $\mathrm{Fe}$, изначально образовавшие нашу планету. Причина такого явления состоит в том, что поступающие из базальтов в раствор химические элементы связываются новыми минералами, формирующимися в этой системе. Такие вторичные образования выступают геохимическими барьерами на пути установления равновесия подземных вод с базальтами, что обеспечивает непрерывность в растворении магматических пород, образование новых геохимических типов воды и серии вторичных минералов [6]. Именно эта внутренняя направленность эволюции делает её похожей на биологическую. Их объединяет близость таких процессов и механизмов как геологическая длительность эволюции, непрерывность взаимодействия, неравновесность, развитие в открытых стационарных системах, получение вещества и энергии из внешних источников, усложнение дочерних продуктов и т.д.

На рис. 1 в качестве примера показана достаточно простая геологическая система, состоящая из анортита, кальцита и природной воды разного состава. Расположение точек на рисунке показывает, что все воды с минерализацией более 0,6-0,8 г/л равновесны или пересыщены к кальциту, но находятся далеко от равновесия с анортитом. Поэтому они растворяют анортит, но осаждают кальцит. Следовательно, кальций из одного минерала через раствор переходит в другой. В течение геологического времени количество анортита в системе будет уменьшаться, а кальцита - расти. При этом содержание кальция в контролирующей с этими минералами воде увеличиваться будет только до предела, определяемого параметрами геохимической среды, так как образование кальцита служит барьером и ограничивает рост $\mathrm{Ca}^{2+}$ в растворе и тем самым не позволяет достигнуть равновесия с анортитом, который поэтому будет растворяться всегда, пока есть вода. 
Принципиально важно, что растворение одних минералов и формирование других происходит под действием не внешних, а только внутренних факторов. Вода всегда растворяет базальты потому, что таковы ее строение и состав, которые несовместимы со структурой базальтовых пород. Именно особенности внутреннего строения воды определяют сущность и характер ее взаимодействия с базальтами и другими алюмосиликатами, которое породило абиогенную эволюцию минерального вещества. Неравновесность воды с базальтами явилась тем спусковым механизмом, который определил эту эволюцию. При этом движущей силой ее выступает вода, точнее энергия её молекулярных связей. Поэтому противоречие воды с базальтами является базовым для всей глобальной эволюции [14].

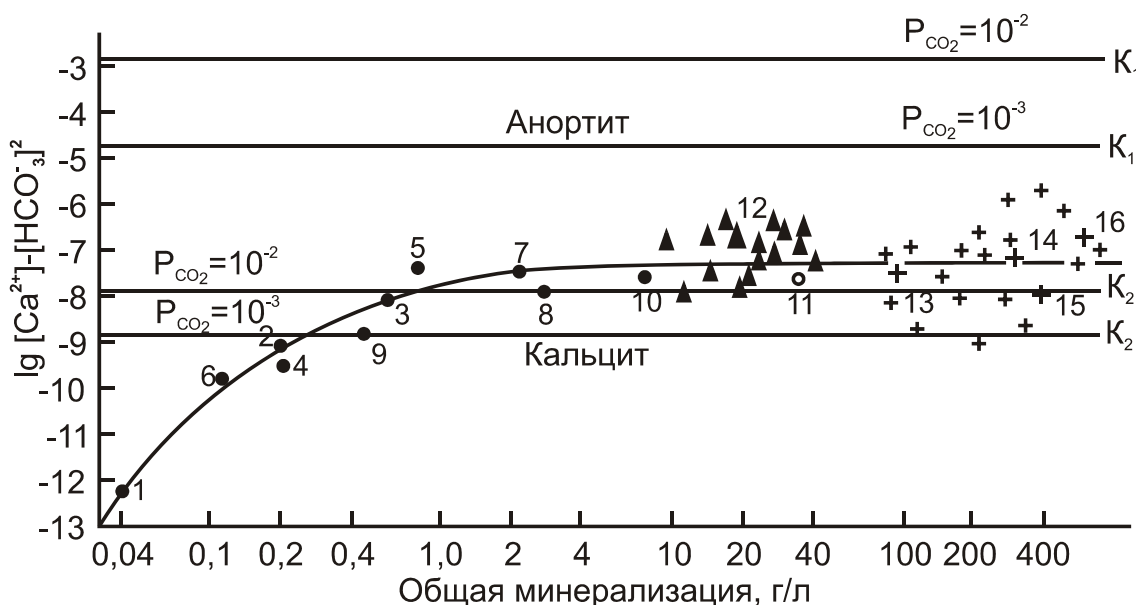

Рис. 1. Степень насыщения подземных вод разной минерализации относительно кальцита и анортита: $\mathrm{K}_{1}$ - константа растворения анортита при разных парциальных давлениях $\mathrm{CO}_{2} ; \mathrm{K}_{2}$ - то же, кальцита; 1-9 - подземные воды зоны гипергенеза разных регионов мира; 10 - соленые воды Донбасса; 11 - океаническая вода; 12 - солёные седиментационные воды Западно-Сибирского артезианского бассейна; 13-16- рассолы Сибирской платформы разной солености

Еще одно важное открытие последних лет, связанное с эволюцией системы вода-порода, заключается в том, что взаимодействие воды с одной и той же породой приводит к образованию разных вторичных минералов. Так, при выветривании и гидротермальном преобразовании, например, анортита могут формироваться гетит, гиббсит, диаспор, бёмит, каолинит, иллит, Самонтмориллонит, кварц, кальцит, арагонит, разные цеолиты, хлориты и т.д. Состав вторичных минералов определяется временем взаимодействия воды с горными породами и типом исходных минералов: первичные или вторичные. Вот только некоторые примеры реакций гидролиза анортита с образованием разных вторичных минералов. 
Как только пресная вода попадает в базальты, начинается процесс растворения анортита и других минералов. В этих условиях образуются наиболее труднорастворимые оксиды и гидроксиды $\mathrm{Al}$ и $\mathrm{Fe}$ по реакции

$$
\mathrm{CaAl}_{2} \mathrm{Si}_{2} \mathrm{O}_{8}+8 \mathrm{H}_{2} \mathrm{O}+2 \mathrm{CO}_{2}=2 \mathrm{Al}(\mathrm{OH})_{3}+\mathrm{Ca}^{2+}+2 \mathrm{HCO}_{3}^{-}+2 \mathrm{H}_{4} \mathrm{SiO}_{4}
$$

Другие химические элементы, включая $\mathrm{Si}$, при этом накапливаются в растворе, и когда достигается равновесие с каолинитом, реакция протекает по другой схеме, хотя исходные вещества остались теми же:

$$
\mathrm{CaAl}_{2} \mathrm{Si}_{2} \mathrm{O}_{8}+3 \mathrm{H}_{2} \mathrm{O}+2 \mathrm{CO}_{2}=\mathrm{Al}_{2} \mathrm{Si}_{2} \mathrm{O}_{5}(\mathrm{OH})_{4}+\mathrm{Ca}^{2+}+2 \mathrm{HCO}_{3}^{-} \text {. }
$$

Но и на этом процесс не останавливается, поскольку неравновесность с анортитом сохраняется. На следующем этапе реакция преобразования анортита протекает по новой схеме (3) с образованием монтмориллонита и кальцита [14].

$1,83 \mathrm{CaAl}_{2} \mathrm{Si}_{2} \mathrm{O}_{8}+11,04 \mathrm{H}_{2} \mathrm{O}+1,66 \mathrm{CO}_{2}=0,17 \mathrm{CaAl}_{2,33} \mathrm{Si}_{3,67} \mathrm{O}_{10}(\mathrm{OH})_{2}+$ $3,26 \mathrm{Al}(\mathrm{OH})_{3}+1,66 \mathrm{CaCO}_{3}+3,04 \mathrm{H}_{4} \mathrm{SiO}_{4}$.

На этой стадии процесс чаще всего заканчивается в зоне гипергенеза, поскольку вода, как правило, покидает горную породу, но если этого не происходит и вода погружается на большие глубины в артезианских бассейнах или по зонам тектонических нарушений, растворение исходной породы продолжается, но с образованием принципиально других минералов: цеолитов, хлоритов, слюд, альбитов, К-полевых шпатов и т.д.

Необходимо также учитывать, что в анортите в виде микропримесей всегда присутствуют и многие другие элементы, в формуле не обозначенные, $\mathrm{Mg}, \mathrm{Na}, \mathrm{K}, \mathrm{Sr}, \mathrm{F}, \mathrm{Fe}, \mathrm{Li}, \mathrm{V}, \mathrm{U}$ и т.д., которые также в процессе гидролиза переходят в раствор и, накапливаясь в нем, при длительном взаимодействии достигают таких концентраций, которые обеспечивают образование и других минералов: гетита, лимонита, магнезита, стронцианита, флюорита, доломита, сидерита, альбита, биотита, мусковита, микроклина, эпидота и т.д. Кроме того, базальты состоят не только из анортита, но и других минералов, каждый из которых обеспечивает раствор своим комплексом элементов, что резко расширяет возможности вторичного минералообразования. Так из небольшого количества растворяемых водой минералов базальтов постепенно складывается целый комплекс новых, которые вместе с одновременно сформированными разными геохимическими типами воды создают окружающий мир на поверхности планеты. Этот мир, в отличие от возникшего ранее - базальтового, более устойчив и хорошо приспособлен к окружающей среде, поскольку вторичные минералы равновесны с водным раствором, создающим эти продукты $[1,15,17]$.

Исключительно важно, что система вода-порода обладает внутренними механизмами эволюции, которые действуют независимо от каких-либо внешних факторов и обеспечивают ее единое целое, внутреннюю обособленность от внешней среды в условиях притока из последней вещества и энергии, поскольку мы имеем дело со стационарной системой. Благодаря наличию таких внутренних, присущих только ей механизмов, без которых ее существование невозможно, она способна развиваться самостоятельно в 
соответствии с законами термодинамики, контролировать направленность своей эволюции, скорость, последовательность и стадийность образования новых вторичных продуктов, их состав, соотношение элементов в растворе и вторичной твёрдой фазе, смену одного продукта другим и т.д. Именно эта внутренняя направленность эволюции делает её похожей на биологическую. Их объединяет близость таких процессов и механизмов как геологическая длительность эволюции, непрерывность взаимодействия, неравновесность, развитие в открытых стационарных системах, получение вещества и энергии из внешних источников, усложнение дочерних продуктов и т.д. [12].

Все это позволило нам сделать вывод, что система вода-порода по комплексу признаков и фундаментальных свойств образует абиогенную диссипативную самоорганизующуюся структуру, которая возникла на самой ранней стадии развития Земли в момент появления свободной воды. Среди фундаментальных ее свойств - непрерывность, неравновесность и нелинейность развития, способность к созданию новых более сложных соединений, которых ранее на земле не было, что является важнейшим признаком эволюции, независимой от внешних факторов и обладающей автономностью, наличием механизмов самоорганизации и т.д. Последнее определяет ее как одну из фундаментальных и базовых систем, обусловивших развитие неорганической материи на предбиотическом этапе эволюционного становления планеты. Именно из этой системы возникло множество других, унаследовавших многие из ее свойств. Сформированные в результате её эволюционного развития химические типы воды и вторичные минералы, приумножаясь, постепенно захватывали геологическое пространство, новые этажи литосферы, формировали новые геохимические среды, которые, в свою очередь, определяли образование новых минеральных фаз, влияющих на характер среды. И этот процесс геологически бесконечен. В этом суть самоорганизации в минеральном царстве, включающем зарождение, рост и пространственно-временное распространение новых структурных форм, минеральных образований, геохимических сред.

Из приведенных фактов следует, что эволюция на нашей планете началась не с возникновения жизни, а с появлением воды, которая эту эволюцию и создала путем непрерывного растворения одних минералов и образования новых с одновременным изменением состава воды [11]. Мы выявили и силу, определяющую эволюцию, которую искал еще Ж.-Б. Ламарк. Оказалось, что такой силой является внутреннее свойство воды - способность растворять все природные соединения и формировать новые [14].

Действительно, всем известно, что диэлектрическая постоянная воды при $25^{\circ} \mathrm{C}$ равна 81 . Это значит, что сила связи разноименных ионов или других частиц, которая имеет место в любом твердом веществе, после помещения последнего в водный раствор уменьшается в 81 раз. Следовательно, сам факт попадания твёрдого тела в водный раствор приводит к появлению силы, которая резко ослабляет и разрывает связи ионов между собой в твердом теле и способствует их переходу в раствор. В настоящее время выявлена 
и физическая природа этой силы, которая состоит в следующем. Жидкая вода, даже абсолютно чистая, согласно квантово-механическим законам является термодинамически неравновесной системой, состоящей из молекул, ионов, атомов, радикалов и других частиц. Неравновесность приводит к непрерывной перестройке структуры воды и протеканию многочисленных колебательно-неравновесных реакций. При этом выделяющаяся энергия не рассеивается полностью в пространстве, как думали раньше, а запасается в энергии межатомных и межмолекулярных связей. Благодаря этой энергии молекулы жидкой воды деформируются: уменьшаются полярный угол между связями О-Н и длина этих связей относительно воды в газовой фазе. Это приводит к перестройке структуры колебательных и вращательных уровней молекул $\mathrm{H}_{2} \mathrm{O}$ и соответственно к их переходу в колебательно-возбужденное состояние [8].

Вследствие постоянных переходов молекул из одного возбужденного состояния в другое в жидкой воде образуются фотоны света от инфракрасного до ультрафиолетового диапазона, которые практически резонансно поглощаются теми же молекулами $\mathrm{H}_{2} \mathrm{O}$, и таким образом осуществляется перераспределение запасенной колебательной энергии по всему объему воды. Говоря иначе, в этих процессах сами молекулы воды выступают в качестве топлива, но «закон сохранения энергии не нарушается, поскольку происходит перераспределение энергии между всеми степенями свободы частиц: электронными, колебательными, вращательными, поступательными и связями между ними» [8. С. 10]. Исходя из этого, Ю.П. Рассадкин приходит к важному выводу о том, что ведущей силой растворения солей в жидкой воде является «облучение ионных кристаллических решеток квантами света, излучаемыми молекулами $\mathrm{H}_{2} \mathrm{O}$, поглощение которых молекулами и атомами кристаллов приводит к уменьшению их коэффициента поляризации $и$, как следствие - крезкому снижению энергии дисперсионных связей между атомами решетки» [С. 447].

Таким образом, между водным раствором и твердым телом всегда имеется энергетический барьер, или сила, которая заставляет воду растворять твердое вещество и формировать новое, включая и то, которого ранее на планете не было. Сила, определяющая растворение твердых тел водой, является внутренней и не зависит ни от каких внешних факторов. Принципиально важно, что в природе нет других сил, которые могли бы остановить процесс растворения, поскольку он составляет сущность этой системы, её внутреннее свойство, без которого она не может существовать. Вода растворяет горные породы не только потому, что они - твердое тело, а главным образом потому, что структура воды несовместима со строением этих пород [12].

Именно особенности внутренней структуры воды определили сущность и характер абиогенной эволюции минерального вещества. Неравновесность воды с базальтами явилась тем спусковым механизмом, который определил эту эволюцию. При этом движущей силой ее выступает энергия межмолекулярных связей в воде. Поэтому противоречие воды с базальтами является 
базовым, определившим начало глобальной эволюции, поскольку оно обусловлено разными генетическими особенностями составляющих эту систему.

Главной причиной эволюции, по нашим данным выступает равновеснонеравновесное состояние системы вода-базальты, главным фактором время, управляющим параметром - состав воды, термодинамической переменной - разность констант реакций растворяющихся и образующихся минералов, движущей силой - облучение растворяемых водой кристаллических и аморфных решеток минералов квантами света, излучаемыми молекулами воды, источником необходимой энергии - запасенная в воде энергия межатомных и межмолекулярных связей [14].

Неравновесность и необратимость играют и еще одну важную роль: они являются основой становления упорядоченности, причиной структурогенеза и эволюции системы в целом. Неравновесность - движущая сила эволюции, которая приводит к изменению необратимых потоков энергии (и вещества), возникающих при стремлении к равновесию эволюционирующих открытых систем. Более того, именно неравновесные системы обладают свойством самоорганизации, которая приводит к переходу от хаоса к порядку, образованию новых диссипативных структур в открытых нелинейных средах [15]. Поэтому путь к сложному - это путь к нелинейным средам с новыми свойствами и более сложным спектром форм и структур. Такой путь возможен в системах, развивающихся вдали от равновесия и обладающих свойствами самоорганизации. Как уже отмечалось, такими свойствами обладает и система вода-порода.

\section{Механизмы биогенного этапа эволюции}

Переходя к проблеме связей эволюции живого с неживым, отметим, что живое не могло возникнуть из обычного камня, поскольку там для этого нет ни питания, ни «постельки для проживания». Понадобилось около 0,7-1 млрд лет для подготовки этих условий. Это и выполнила система вода-базальты. За это время на поверхности земли возникли разнообразные вторичные минеральные продукты - коры выветривания и не менее многочисленные геохимические типы воды, сформировались разные геохимические среды по солености, pH, Eh, содержанию различных форм и соединений химических элементов в воде, разные типы вод, включая физически связанные, которые отличаются иными термодинамическими свойствами.

Следовательно, живые системы с самого начала развивались в средах, созданных абиогенным путем, и поэтому они унаследовали основные механизмы эволюции косной материи. Действительно, все живое, как и косное, развивается в открытых стационарных системах, которые получают вещество и энергию из внешних сред. Такие системы всегда являются неравновесными и самоорганизующимися [6]. То вещество, которое потребляют живые организмы, неравновесно со средой живого и оно должно быть пере- 
варено (растворено) прежде, чем примет участие в синтезе новых соединений. Иначе говоря, появившись в результате фотосинтеза, молекулы органического вещества оказались в той или иной водной среде, в которой уже шло формирование разных вторичных минералов, но эта среда была чужда для новых органических соединений, так как они с этой средой неравновесны. Поэтому начались процессы его растворения по механизму гидролиза и образования новых органических соединений, равновесных с конкретной средой. Поскольку геохимические среды были разные, формировавшиеся новые продукты тоже были разные. Следовательно, появление в абиогенной среде простых органических молекул типа $\mathrm{CH}_{2} \mathrm{O}$ запустило новый гигантский процесс: формирование более сложных и более устойчивых применительно к конкретным условиям среды органических образований, которые постепенно привели к развитию новых многочисленных органических форм. Так, наряду с минеральными, вода стала формировать органические соединения, которые, усваивая растворенные в воде химические элементы, сформировали новый, более сложный тип органо-минеральных образований, равновесных с биогеохимической средой. И сегодня равновесие этих двух разных комплексов поддерживается через водный раствор. В этих условиях наиболее «мудрыми» оказались растения, которые изначально приспособились к составу готового природного раствора как питательного средства. При этом условия окружающей среды существенно не менялись: не среда приспосабливалась к новым условиям, а появившаяся органика перестраивалась к реальным условиям среды. Такое изменение присходило в условиях равновесно-неравновесного состояния системы вода-органическое вещество, в области, далёкой от равновесия. Таким путём и сегодня обеспечивается непрерывный синтез в водном растворе более сложных равновесных со средой органических соединений, что гарантирует их стабильность только в строго определённых биохимических средах.

Таким образом, растения получают солнечную энергию в процессе фотосинтеза, а питательные вещества - из воды, которая в свою очередь берет их из горных пород или атмосферы. Так организуется взаимодействие всех ведущих стихий окружающего мира: воды, породы, газов и органических соединений, на что обращал внимание еще В.И. Вернадский [2]. Но и здесь вода остается главным фактором внутренней эволюции так как она не только контролирует состав образующихся всех вторичных органических соединений, характер среды, энергетическое состояние системы, направленность эволюции и т.д., но и регулирует взаимоотношения двух систем вода-порода и вода-органическое вещество, т.е. одной - мертвой, другой живой.

Животные, в отличие от растений, питаются не только водой, но и растительной и мясной пищей, которая также неравновесна со средой живого организма и не может усваиваться без предварительной подготовки. Для перевода принимаемой пищи в растворенное состояние у животных имеется специальная система - желудочно-кишечный тракт. Только в растворённом 
состоянии ионы и молекулы поступают непосредственно в организм, у теплокровных животных - в кровь. В конечном счете, любой живой организм непрерывно получает пищу в растворённом виде. Увеличение концентрации в водной среде организма поступающих из внешней среды соединений обеспечивает образование зародышей многочисленных сложнейших органических веществ в строгом соответствии с законами термодинамики. И здесь главным фактором выступает состав раствора, а все формирующиеся в этих условиях вторичные образования равновесны со средой, в которой рождаются, и потому остаются устойчивыми в течение достаточно длительного времени.

Итак, во всех главных системах (царствах) мира - минеральной, растительной, животной и человека - действуют одни и те же принципы эволюции, обусловленные одними причинами и механизмами. Эти системы развиваются только в водной среде при химическом участии молекул воды в равновесно-неравновесных внутренне противоречивых условиях, далеких от равновесия. Вода всегда растворяет одни исходные соединения (горные породы, органические вещества растений и животных, газы) и формирует новые, включая такие, которых на планете ранее не было. Механизм растворения также одинаков - это гидролиз.

Соответственно, истоки эволюции живой материи тоже связаны с водным раствором, но более сложным по составу относительно минерального мира. Но эта сложность - результат эволюции, начавшейся в минеральном царстве, ключевым фактором которой выступает растворение водой одних соединений и формирование других, более устойчивых в возникающих новых средах. Превращение одного твёрдого соединения в результате растворения и осаждения в другое - главный механизм эволюичии, который непрерывно перестраивает существующий мир и создает новый, более сложници.

\section{Общность эволюции живой и неживой материи}

Итак, в живых и неживых системах нашей планеты механизмы любой эволюции определяет вода. В условиях непрерывного взаимодействия воды с органическими и минеральными соединениями химические элементы в водном растворе быстро перераспределяются по всему её объёму и получают принципиально новые возможности для взаимодействия с другими его элементами, ионами, комплексами, что ведёт к формированию разнообразных молекулярных ансамблей и ассоциаций, включая принципиально новые. Все привычные нам сегодня органические и неорганические соединения когда-то были первыми и новыми. И в наше время их образование продолжается.

Начало любого природного вторичного продукта обусловлено поступающими в раствор элементов из уже существующих соединений. В воде элементы, атомы, молекулы из разных источников имеют возможность встречаться и объединяться в новые ансамбли будучи еще в растворенном виде. 
Но по мере их роста, увеличения объёма и веса в благоприятной среде они трансформируются в зародыши твёрдой фазы. Современная техника позволяет под микроскопом увидеть такие нано-соединения. В качестве примера на рис. 2 показаны оксиды железа, обнаруженные в чистых питьевых водах в районе г. Вашингтона [18].

Таким образом, любое «свидание» ионов в растворе при благоприятных термодинамических условиях заканчивается возникновением новых соединений. Поскольку таких "свиданий" много, то они обеспечивают рождение новой среды и, соответственно, нового мира, который есть результат взаимодействия ионов, атомов, молекул в благоприятном для этого водном растворе.

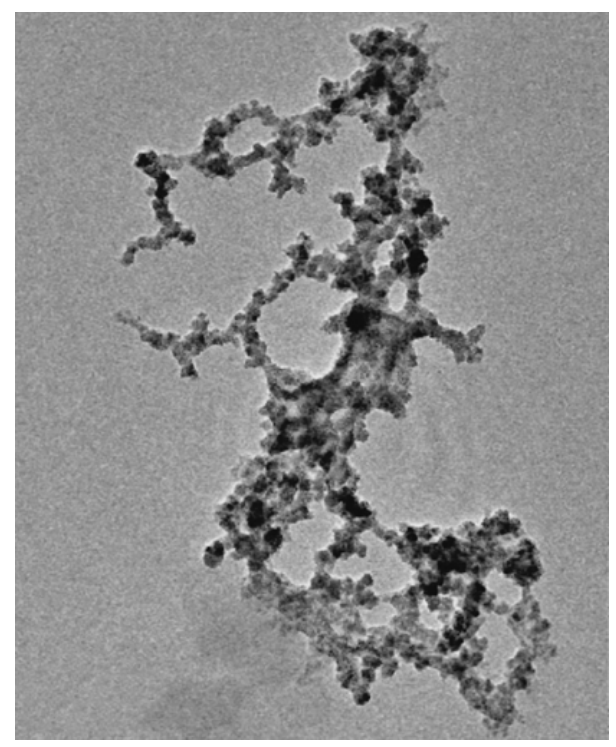

Рис. 2. Наночастицы оксидов железа, найденные в питьевых водах района, Вашингтон, США

Рождённые в водном растворе вторичные образования появились потому, что для них сложились благоприятные условия, которые гармонируют с ними по всем параметрам - структуре, составу, строению, физическим, химическим, биохимическим свойствам. Сформировавшиеся вторичные продукты существуют до тех пор, пока сохраняется породившая их среда. В свою очередь, такая среда будет поддерживаться, если взаимодействие в системе вода-порода-газ-органическое вещество происходит при тех же параметрах, которые обеспечили появление вторичного продукта. Только в случае равновесия со средой его объём непрерывно будет расти, захватывать окружающее пространство и оставаться стабильным и стойким в изменяющемся внешнем мире. 
Согласованность параметров окружающей среды и нового соединения залог их устойчивости, которая могла возникнуть только в открытой системе, в изолированном и ограниченном пространстве, в котором процессы, создавшие их, стабилизированы: обеспечено строгое динамическое и химическое равновесие, существенно не меняются скорость поступления и количество воды в системе, растворяется близкое количество минералов, газов, органических веществ, стабильно формируются новые вторичные продукты и т.д. Меняется только одно - состав воды, которая продолжает накапливать те химические элементы, которые не достигли равновесия ни с одной из твёрдых фаз. Это обстоятельство приводит к тому, что характер твёрдой фазы со временем меняется и появляется очередная дочерняя система иного состава, структуры, строения. Это и есть механизм глобальной эволюции, характер которой со временем меняется.

Целенаправленное преобразование мира (неживого и живого), которое началось с появлением воды и которое до сих пор только набирает обороты, не могло быть случайным, поскольку зиждется оно на фундаментальных законах мироздания. В этом грандиозном шоу нет места случайностям, а есть строго выверенное поступательное движение, укладывающее кирпичики мироздания в строгом соответствии с внутренней структурой возникающих соединений и их ансамблей.

Эволюция жизни, как и любая другая, потому и возможна, что в ней нет случайностей, которые ведут не к порядку, а к хаосу. Ни одно соединение в растворе (ион, ионная пара, комплекс) не может появиться случайно, вне законов термодинамики. Это касается и любого вторичного минерала, геохимического типа воды, гидрогенно-минерального комплекса, живого существа, всех его органов и жизни в целом.

При таком подходе, вопреки взглядам Р. Докинза и многих других биологов, эволюция не является исключительным, произошедшим только один раз на Земле, и тем более во всей Вселенной благодаря случайному стечению многих обстоятельств событием. Эволюция предрешена естественными причинами - появлением воды, взаимодействие которой с базальтами является не случайным, а строго закономерным, обусловленным фундаментальными законами термодинамики, по которым развивается система водапорода. Формирование вторичных минералов в строгом соответствии с геохимической средой, с её термодинамическими параметрами обусловлено внутренней сущностью развития этой системы вне зависимости от какихлибо внешних факторов. Однажды начавшись, этот процесс продолжается уже в течение 4,5 млрд лет исключительно стабильно, так как базируется на фундаментальных законах мироздания.

Абиогенная эволюция подготовила почву для возникновения и эволюции жизни, которая, в свою очередь, не только унаследовала основные механизмы геологической эволюции, но и создала множество принципиально новых, ещё более сложных соединений и процессов, таких как репликация, клетка, движение, зрение, сознание, мозг и т.д. Лестница жизни строилась, 
непрерывно усложняясь, но сохраняя исходные базовые позиции, определяемые глубоким антагонизмом между водным раствором и базальтами, позже унаследованным системой вода-органическое вещество [14].

Все сказанное показывает, что глобальная эволюция в первом приближении состоит как минимум из 3 этапов (рис. 3). На первом этапе она определяется взаимодействием воды с горными породами, преимущественно базальтами (ветвь А), на втором добавляется взаимодействие с продуктами фотосинтеза (ветвь В), на третьем - взаимодействие с возникшей более сложной органикой (белками, углеводами, жирами и др.) (ветвь С). На всех этапах эволюции ведущим компонентом сохраняется вода, но разного состава. И взаимодействует она со все более сложными соединениями, ею созданными. Следовательно, эволюция вещества на Земле является результатом непрерывного усложнения состава, прежде всего воды и водной среды, которые обеспечивают постепенное усложнение и всех вторичных продуктов.

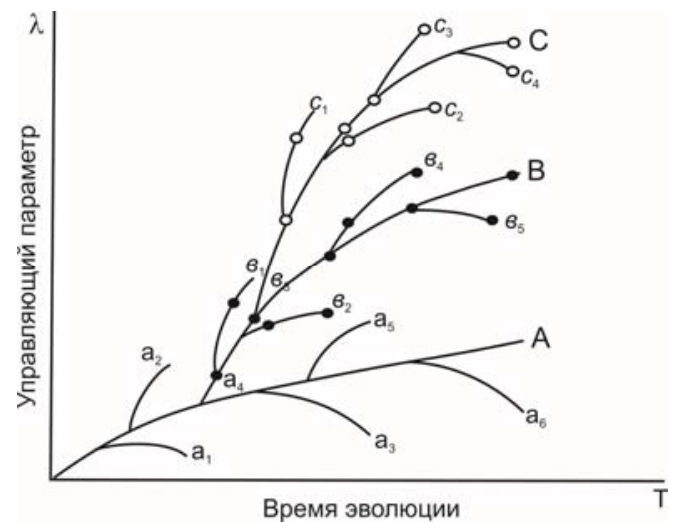

Рис. 3. Схема последовательного усложнения состава водного раствора в ходе глобальной эволюции. Материнские системы:

$A$ - вода - порода; $B$ - вода - растения; $C$ - вода - животные дочерние системы: $\mathrm{a}_{1}-\mathrm{a}_{\mathrm{n}}-$ ветви $\mathrm{A} ; \mathrm{b}_{1}-\mathrm{b}_{\mathrm{n}}-$ ветви $\mathrm{B} ; \mathrm{c}_{1}-\mathrm{c}_{\mathrm{n}}-$ ветви $\mathrm{C}$

Нелинейность, неравновесность, необратимость, открытость рассматриваемых нами систем обеспечили их самоорганизацию и непрерывность усложнения, которое выступает центральным мотивом всего процесса прогрессивной эволюции нашей планеты. Механизмы сборки сложного, цепные реакции усложнения, принципы создания сложных структур из простых, природа направленности эволюционных процессов к усложнению и т.д. имеют место в косных, биокосных, клеточных, живых, социальных и других системах [6]. При этом главным компонентом, который объединяет все эти системы, является вода, контролирующая ключевую стадию эволюции - рождение новых соединений. Именно вода является связующим звеном живой и неживой материи. Обнаружение единого связующего звена косной, биокосной и биогенной материи, преемственности в их 
развитии, которые ранее казались невозможными, открывает принципиально новые пути познания окружающего мира, механизмов его постоянного усложнения. Все эти процессы развиваются в первую очередь в зоне гипергенеза.

\section{Заключение}

Зона гипергенеза - арена непрерывных преобразований всех минеральных и органических веществ. Если же на эту зону смотреть шире, то и социальных. Более того, с этой зоной связана и ноосфера. Такое её разнообразие и определило огромное количество разных наук, которые изучают эту зону. В этой ситуации особенно важно разобраться в характере связей, которые имеют место между разными объектами, процессами, факторами, средами и т.д. Научной базой для этого является учение о глобальной эволюции, которое расставляет по своим местам все силы, механизмы, процессы, управляющие этим самым грандиозным явлением на нашей планете. Все это и помогает глубже понять существующие связи между разными науками, изучающими не только зону гипергенеза, но и весь окружающий мир. Поэтому учение об эволюции служит базой для интеграции разных наук, которая нас ожидает в ближайшее время.

\section{Лumepamypa}

1. Алексеев В.А., Рыженко Б.Н., Швариев С.Л., Зверев В.П., Букаты М.Б., Мироненко M.B., Чарыкова M.B., Чудаев О.В. Геологическая эволюция и самоорганизация системы вода-порода. Т. 1. Система вода-порода в земной коре: взаимодействие, кинетика, равновесие, моделирование. Новосибирск : Изд. СО РАН, 2005. 244 с.

2. Вернадский В.И. История природных вод. М. : Наука, 2003. 751 с.

3. Докинз Р. Самое грандиозное шоу на Земле. Доказательства эволюции. М.: Астрель; Corpus. 2013. $496 \mathrm{c}$.

4. Кунин Е. Логика случая: О природе и происхождении биологической эволюции. М.: Центрполиграф, 2014. 1338 с.

5. Николис Г., Пригожин И. Самоорганизация в неравновесных системах. М. : Мир, 1979. $512 \mathrm{c}$.

6. Николис Г., Пригожин И. Познание сложного. М. : Мир, 1990. 342 с.

7. Пригожин И., Стенгерс И. Порядок из хаоса. Новый диалог человека с природой / пер. с англ. 4-е изд. М. : УРСС, 2003. 312 с.

8. Рассадкин Ю.П. Вода обыкновенная и необыкновенная. М. : Галерея СТО, 2008. 840 с.

9. Хаин B.E. Взаимодействие атмосферы, биосферы и литосферы - важнейший процесс в развитии Земли // Вестник РАН. Т. 77, № 9. 2007. С. 794-797.

10. Швариев С.Л. Фундаментальные механизмы взаимодействия в системе вода - горная порода и ее внутренняя геологическая эволюция // Литосфера. 2008. № 6. С. 3-24.

11. Швариев С.Л. С чего началась глобальная эволюция? // Вестник РАН. 2010. № 3. C. $235-244$.

12. Швариев С.Л. Внутренняя эволюция геологической системы вода-порода // Вестник PAH. 2012. № 3. C. 242-251.

13. Швариев С.Л. Вода как главный фактор глобальной эволюции // Вестник РАН. 2013. T. 83, № 2. C. 124-131. 
14. Швариев С.Л. Основное противоречие, определившее механизмы и направленность глобальной эволюции // Вестник РАН. 2015. Т. 85, № 7. С. 632-642.

15. Швариев С.Л., Рыженко Б.Н., Алексеев В.А., Дутова Е.М., Кондратьева И.А., Копылова Ю.Г., Лепокурова О.Е. Геологическая эволюция и самоорганизация системы вода-порода. Т. 2. Система вода-порода в условиях зоны гипергенеза. Новосибирск : СО РАН, 2007. 389 c.

16. Lovelock J. Living planet // Geoscientist. 2006. V. 16. № 10. P. 1060-1064.

17. Shvartsev S.L. Geochemistry of fresh groundwater in the main landscape zones of the earth //Geochem. Intern. 2008. V. 46, № 13. P. 1285-1398.

18. Wigginton N.S., Haus K.L., Hochella M.F. Aquatic environmental nanoparticles // J. of Environ. Monitoring. 2007. V. 9, № 12. P. 1306-1316.

\section{Автор:}

Шварцев Степан Львович, доктор геолого-минералогических наук, профессор кафедры гидрогеологии, инженерной геологии и гидрогеоэкологии Томского политехнического университета, директор Томского филиала Института нефтегазовой геологии и геофизики СО РАН, Томск, Россия.

E-mail: tomsk@ipgg.sbras.ru

Geosphere Research, 2016, 1, 66-84. DOI: 10.17223/25421379/1/6

\section{S.L. Shvartsev}

Tomsk Branch of Trofimuk Institute of Petroleum Geology and Geophysics, Siberian Division of Russian Academy of Sciences, National Research Tomsk Polytechnic University, Tomsk, Russia

\section{IMPERATIVE MECHANISMS OF FORMATION OF THE SECONDARY PRODUCTS IN THE HYPERGENESIS ZONE: COMMONALITY AND RE- LATION OF THEIR ORIGIN}

It is shown in the paper that main processes of the global evolution began with waterbasalts interaction in the upper part of the Earth crust. The contradictory equilibrium-non-equilibrium system has appeared, which is able to develop eternally by strict thermodynamics laws in spite of any external factors. Herein, water acts as a main factor in system transformation. After photosynthesis appeared, the organic substances got into different geochemical environments created by water-basalts interaction. That defined their further transformation in a way similar to the one that ensured rock evolution. In this case, the common denominator between inert substances and non-living material is water, which controls the main stage of evolution in geological and biological systems, which is formation of fundamentally new compounds. Further, it is shown that abiotic evolution paved the way for initiation and evolution of life, which in turn not only inherited the main geological evolution mechanisms but also created a variety of fundamentally new and more complex compounds and processes such as replication, cells, etc. The global evolution at a first approximation consists of three stages. At the first stage, it was determined by the interaction of water with rocks, essentially with basalts, at the second stage the interaction with photosynthesis products was added, at the third one the interaction with resultant more complex organic matter (proteins, carbohydrates, fats and etc.) took place.

A fundamental component of evolution at all the stages remained water, but water with different chemical composition. Moreover, water interacts with increasingly complex compounds created by it. Non-linearity, non-equilibrium state, irreversibility and openness of these 
systems provided their self-organization and continuous complication, which is the main motive of entire progressive evolution process of our planet. Construction mechanisms of complex compounds take place in inert substances, non-living material, cellulite, alive, social and other systems. Detecting one denominator between inert substances, non-living material and biogenesis matter, and succession/continuity in their development, which seemed to be impossible before, opens fundamentally new ways for learning the world.

Keywords: supergene zone, the global evolution, thermodynamic equilibrium, Hydrogeochemistry, secondary mineral formation, the system water-rock, dissolving, groundwater.

\section{References}

1. Alekseev V.A., Ryzhenko B.N., Shvartsev S.L., Zverev V.P., Bukaty M.B., Mironenko M.V., Chary'kova M.V., Chudaev O.V. Geologicheskaya evolyutsiya $i$ samoorganizatsiya sistemy voda-poroda. T. 1. Sistema voda-poroda v zemnoy kore: vzaimodeystvie, kinetika, ravnovesie, modelirovanie [Geologic evolution and selforganization of the water-rock system. V.1. The water-rock system in the Earth's crust: Interaction, kinetics, equilibrium and modeling]. Novosibirsk: SB RAS Publ., 2005. 244 p. In Russian.

2. Vernadsky V.I. Istoriya prirodnykh vod [History of natural waters]. Moscow: Nauka, 2003. 751 p. In Russian.

3. Dawkins R. The greatest show on earth the evidence for evolution. Free Press. Transworld, 2009. $470 \mathrm{p}$.

4. Koonin E.V. The logic of chance. The nature and origin of biological evolution. New Jersey: FT Press Sci, 2011. 528 p.

5. Nicolis G., Prigogine I. Self-organization in nonequilibrium systems. New York: John Wiley and Sons, 1977. 303 p.

6. Nicolis G., Prigogin I. Exploring complexity. An introduction. San-Francisco: Freeman, 1989. № 6. V. 106. pp. 467-482.

7. Prigogine I, Stengers I. Order out of chaos Mains new dialogue with nature. London: Heineman, 1984. $432 \mathrm{p}$.

8. Rassadkin Yu.P. Voda obyknovennaya $i$ neobyknovennaya [Water usual and unusual].Moscow: Galereya STO, 2008. 840 p. In Russian.

9. Khain V.E. The interaction between the atmosphere, the biosphere, and the lithosphere is the most important process in the earth's development // Herald of the Russian Academy of Sciences. 2007. № 5.V. 77. pp. 470-473.

10. Shvartsev S.L. Fundamental'nye mekhanizmy vzaimodeystviya $v$ sisteme voda - gornaya poroda $i$ ee vnutrennyaya geologicheskaya evolyutsiya [Fundamental mechanisms of interaction in the water rock system and its interior geological evolution] // Lithosphere. 2008. №6. pp. 3-24. In Russian.

11. Shvartsev S.L. Where did global evolution begin? // Herald of the Russian Academy of Sciences. 2010. V. 80. № 2. pp. 235-244.

12. Shvartsev S.L. The internal evolution of the water-rock geological system // Herald of the Russian Academy of Sciences. 2012. V. 82. № 2. pp. 134-142.

13. Shvartsev S.L. Water as the main factor of global evolution. // Herald of the Russian Academy of Sciences. 2013. V. 83. № 1. pp. 78-85.

14. Shvartsev S.L. The basic contradiction that predetermined the mechanisms and vector of global evolution // Herald of the Russian Academy of Sciences. 2015. V. 85. № 4. pp. 342351.

15. Shvartsev S.L, Rizhenko B.N., Alekseev V.A., Dutova E.M., Kondratiev I.A., Kopylova Y.G., Lepokurova O.E. Geologicheskaya evolyutsiya i samoorganizatsiya sistemy voda-poroda. t.2. Sistema voda-poroda v usloviyakh zony gipergeneza [Geological 
evolution and self-organization of the system water-rock. V. 2. The system water-rock under the supergene zone]. Novosibirsk: SB RAN, 2007. 389 p. In Russian.

16. Lovelock J. Living planet// Geoscientist. 2006. V. 16. № 10. pp. 1060-1064.

17. Shvartsev S.L. Geochemistry of fresh groundwater in the main landscape zones of the earth. //Geochem. Intern. 2008. V. 46. № 13. pp. 1285-1398.

18. Wigginton N.S., Haus K.L., Hochella M.F. Aquatic environmental nanoparticles // J. of Environ. Monitoring. 2007.V. 9. № 12. pp. 1306-1316.

\section{Author:}

Shvartsev Stepan L., Dr. Sci. (Geol.-Miner.), Professor, Department of Hydrogeology, Engineering Geology and Hydrogeoecology, Tomsk Polytechnic University, Director of Tomsk Branch of Trofimuk Institute of Petroleum Geology and Geophysics, SB RAS, Tomsk, Russia. E-mail: tomsk@ipgg.sbras.ru 